\title{
MANFAAT EKSTRAK DAUN PEPAYA UNTUK MENGHILANGKAN SAKIT PERUT SAAT HAID
}

\author{
Lara Syakhila* ${ }^{1}$ \\ ${ }^{1}$ Pendidikan Kimia, FMIPA, Universitas Negeri Padang, Indonesia
}

*Email : larasyakila12@gmail.com

\begin{abstract}
ABSTRAK : Study ini bertujuan untuk membuat ekstrak daun pepaya untuk menghilangkan sakit perut saat haid.Metode yang dilakukan adalah eksperimen dan uji aktivitas katalitik secara langsung.Tahapan pertama dilakukan dengan penghalusan daun pepaya dan diambil ekstraknya.Uji aktivitas langsung dilakukan dengan variasi meminum segelas ekstrak daun pepaya saat datangnya haid dan rasa sakit perut tersebut.Hasil eksperimen membuktikan bahwa ekstrak daun pepaya dapat menghilangkan sakit perut saat haid.Kondisi optimum ekstrak daun papaya meminum segelas ekstraknya pada saat haid.Penyembuhan ini diduga karena aktivitas katalitik rebusan daun pepaya untuk menghilangkan sakit perut saat datangnya haid.
\end{abstract}

Kata kunci : daun pepaya,sakit perut,haid,katalitik,ekstrak daun pepaya

\section{PENDAHULUAN}

Reaksi kimia itu sangat penting.Dalam reaksi kimia terdapat perubahan reaksi kimia yang diantaranya yaitu perubahan suhu,bau,suhu,endapan dan terbentuknya gelembung gas[1][2][3].Reaksi kimia tidak mempertimbangkan waktu hanya melakukan suatu proses internal sehingga menghasilkan perubahan-perubahan.Terjadinya perubahan tersebut diakibatkan oleh perubahan susunan komponen[4][5].Reaksi kimia itu sangat penting bagi kehidupan,karena dengan reaksi kimia menghambat terjadinya pembusukan.Dalam reaksi kimia kita juga dapat mengetahui manfaat-manfaat dari alam terutama yang dapat dimanfaat bagi kesehatan secara alami.Seperti pemanfaatan tumbuh-tumbuhan yang ekstraknya diambil untuk dijadikan obatobatan[6].

Pemanfaatan tumbuh-tumbuhan untuk dijadikan obat-obatan ini dapat mengurangi biaya yang besar untuk menyembuhkan sebuah penyakit[7].Dengan bermodalkan bagian-bagian tertentu dari tumbuhtumbuhan tersebut merupakan suatu alternatif yang sangat mudah untuk menyembuhkan suatu penyakit[8].Namun tidak semua tumbuh-tumbuhan 
dapat digunakan untuk alternative pengobatan secara alami,ada juga efek samping atau zat berbahaya yang terkandung di dalam tumbuh-tumbuhan tersebut,untuk menghindari maka dilakukannya sebuah eksperimen untuk membuktikan khasiat dari tumbuh-tumbuhan tersebut[9][10].

Salah satu tumbuh-tumbuhan yang sangat sering digunakan untuk penyembuhan suatu penyakit ialah ekstrak dari daun pepaya[11][12].Bukan hanya daun saja yang memiliki khasiat bagi penyembuhan suatu penyakit tetapi buahnya[13] juga dapat digunakan untuk membantu lancarnya buang air besar.Daun pepaya bukan hanya dijadikan alternatif pengobatan suatu penyakit,daun pepaya juga bisa dijadikan sayuran[14] sesuai dengan khas dari suatu daerah.

Menurut masyarakat di perkampungan daun pepaya bukan hanya dapat menghilangkan sakit perut saat haid[15][16],daun pepaya juga dapat membantu pencegahan kanker terhadap manusia,menurunkan tekanan darah[17] tinggi[18],dan bagi ibu hamil yang baru saja melahirkan jika meminum ekstrak daun pepaya dapat meningkatkan tenaga terhadap ibu tersebut.Dan ada juga yang mengatakan bahwa daun[19] pepaya dapat meningkatkan nafsu makan baik pada orang dewasa maupun anakanak.Ekstrak daun pepaya ini juga banyak digunakan bagi orang-orang yang susah dalam hal meminum obat[20] yang diberikan oleh dokter.

Berdasarkan informasi yang di dapat dari masyarakat bahwa ekstrak[21] daun pepaya dipercaya dapat menghilangkan sakit perut saat datangnya haid,inilah yang membuat saya ingin membuktikan mengenai ekstrak daun pepaya dapat menghilangkan sakit perut saat datangnya haid.Dimana tujuan dari penilitian ini adalah untuk membuktikan apakah benar pengaruh [22] ekstrak daun pepaya dapat menghilangkan[23]sakit perut saat datangnya haid.

\section{METODE PENELITIAN}

2.1 Pada penelitian tentang studi kajian terhadap ekstrak daun pepaya dapat menggunakan alat dan bahan sebagai berikut:

Alat:

1.Blender (miyako)

2.Kamera (xiaomi note $4 \mathrm{x}$ )

3.Sendok (stainless) 


\section{Gelas (KMA Indonesia)}

\section{Pisau (stainless)}

Bahan:

\section{Daun pepaya 2 lembar}

2.Air Aqua $100 \mathrm{~mL}$

\section{Jahe 0,5 gram}

Prosedur kerja dari study ini : menyiapkan 2 lembar daun pepaya kemudian daun pepaya tersebut dicuci dengan air,setelah dicuci dengan air lalu daun pepaya tersebut dipotong beberapa bagian supaya memudahkan pada saat memblendernya.Daun pepaya yang sudah dipotong beberapa bagian tersebut dimasukkan ke dalam blender lalu ditambah air sebanyak 100 mL,tambahkan jahe sebanyak 0,5 gram.Haluskan semua bahan,setelah halus dituangkan ke dalam gelas.Hasil yang di dapatkan dari ekstrak daun pepaya adalah satu gelas atau setakar dengan 200 mL.Kemudian hasil ekstrak tersebut diminum oleh penderita sakit perut tersebut sebanyak satu gelas dan menanyakan kepada penderita[24] setelah 30 menit awal pada saat meminumnya.

\section{A.Prosedur Kerja}

a. Penyiapan sampel

-sampel diambil di halaman rumah yang berada di kampung Tampang kecamatan Lubuksikaping Kabupaten Pasaman
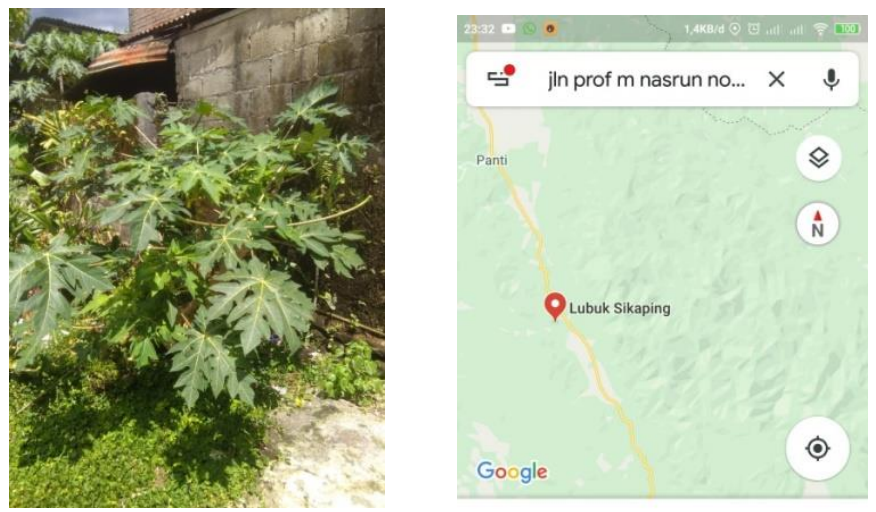

-sampel diambil sebanyak 2 lembar dan dicuci 


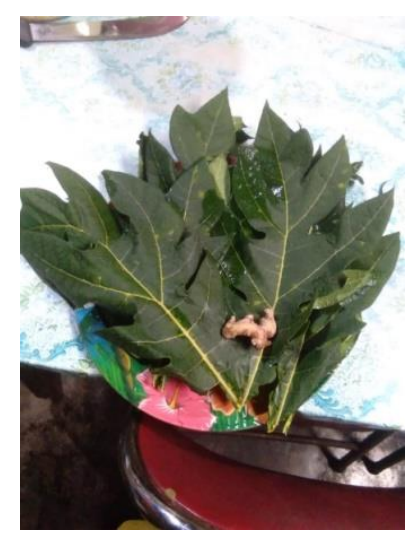

b. Pembuatan ekstrak

-sampel dipotong-potong supaya memudahkan dalam hal penghalusan menggunakan blender

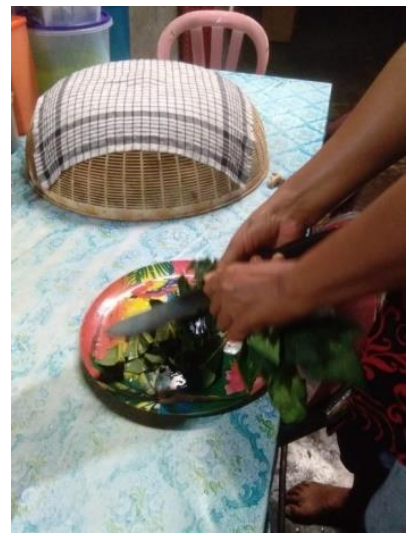

-setelah di potong-potong sampel dimasukkan ke dalam blender untuk dihaluskan,sebelumnya menambahkan 0,5 gram jahe ke dalam sampel untuk dihaluskan,lalu dihaluskan sampai halus agar mendapatkan ekstraknya

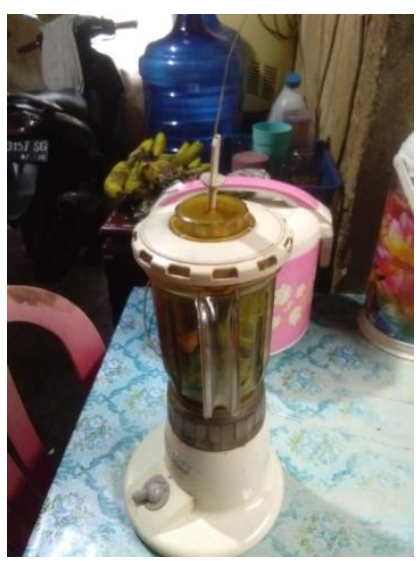


-menuangkan ke dalam gelas hasil dari ekstrak sampel tersebut

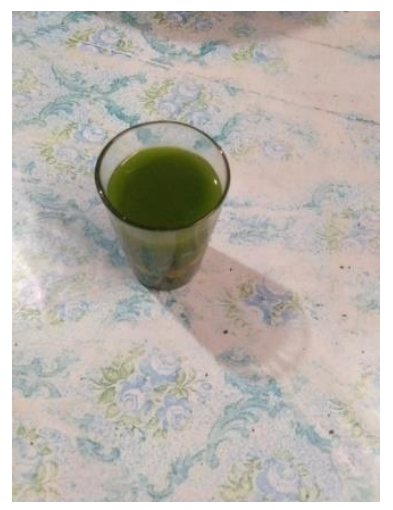

\section{c. Pengujian}

-memberikan kepada penderita hasil dari ekstrak daun pepaya untuk membuktikannya

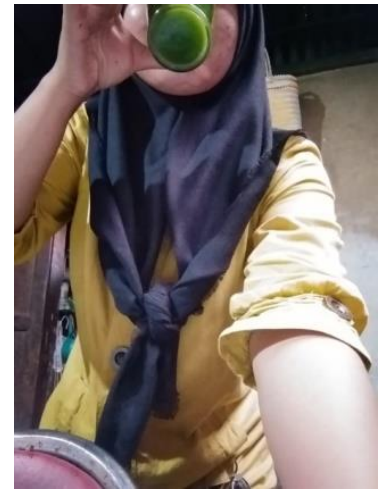




\section{Metode ini dapat dibuat secara diagram alir}

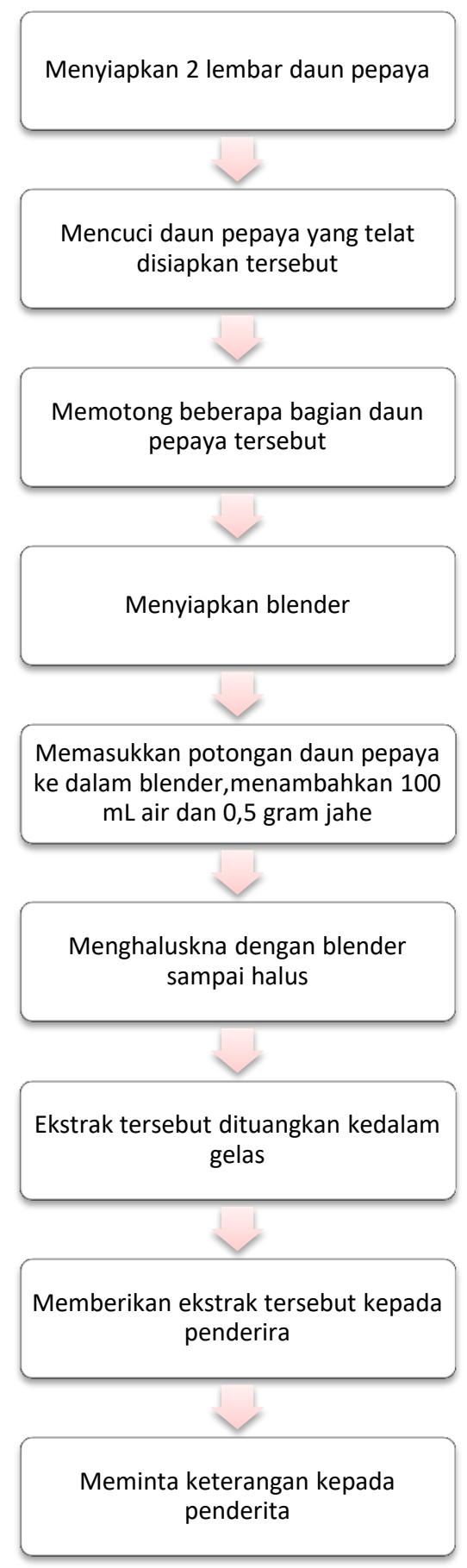




\section{HASIL}

Hasil pembuatan ekstrak daun pepaya dari $100 \mathrm{~mL}$ air diperoleh ekstraknya sebanyak $200 \mathrm{~mL}$ atau setara satu gelas.

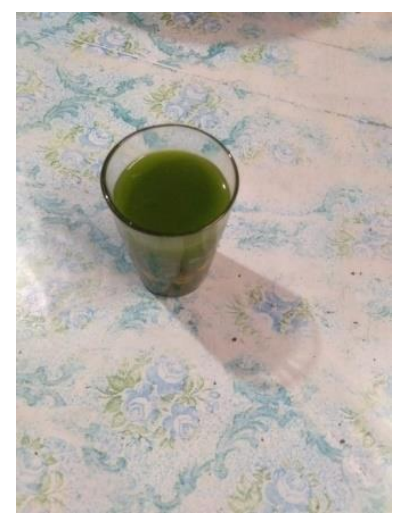

\section{Hasil Uji Coba}

Pengujian ini dilakukan kepada orang yang sedang haid dan merasakan sakit perut,dan ternyata ekstrak daun pepaya ini berhasil menghilangkan rasa sakit perut sesuai table berikut:

Tabel 1

\begin{tabular}{|c|c|c|}
\hline NO & $\begin{array}{c}\text { WAKTU SETELAH } \\
\text { MEMINUM } \\
\text { EKSTRAK }\end{array}$ & KADAR SAKIT \\
\hline 1 & 30 menit & $* * * * *$ \\
\hline 2 & 1 jam & $* * * *$ \\
\hline 3 & 90 menit & $* *$ \\
\hline 4 & 2 jam & $*$ \\
\hline
\end{tabular}

Keterangan :

- $* * * * *=$ sakit

- $* * * *$ = masih sakit,

- $* * \quad=$ sakit sudah mulai hilang

- $\quad$ = sakit hilang 


\section{PEMBAHASAN}

Dalam melakukan eksperimen sampel didapatkan dikampung Tampang kecamatan Lubuksikaping kabupaten Pasaman.Tumbuhan pepaya sangat banyak ditemukan di Indonesia,tumbuhan ini merupakan tumbuhan yang sering ditanam oleh masyarakat pada pekarangan rumah ataupun di kebun yang dimiliki oleh masyarakat setempat.Namun untuk memperoleh daun pepaya yang bagus untuk membuat ekstrak daun pepaya sangat susah didapatkan karena kadang banyaknya daun pepaya yang terserang hama sehingga menyebabkan masyarakat tidak bisa menggunakan daun pepaya tersebut untuk diolah.

Daun pepaya bukan hanya digunakan hanya untuk membuat obatobatan,tetapi ada juga yang membuatnya sebagai bahan olahan makanan seperti menjadikan daun pepaya tersebut sebagai sayuran untuk dimakan.Berbagai macam sayuran yang dibuat oleh masyarakat,masyarakat mempercayai bahwa memakan sayur dari daun pepaya dapat mengurangi resiko dari penyakit kanker dan juga dapat meningkatkan nafsu makan baik bagi orang dewasa maupun anak-anak.

Dalam proses pembuatan ekstrak daun pepaya sangat mudah dilakukan,cukup menghaluskan daun pepaya yang diambil lalu menambahkan dengan air dan meminumnya,banyak yang menambahkan jahe untuk menciptakan rasa yang tidak pahit agak penderita sakit tidak mual meminumnya.Dalam proses pembuatan daun pepaya yang akan digunakan harus benar-benar dalam keadaan baik dan tidak terserang hama dan juga daunnya harus segar dan hijau,daun yang digunakan bukan pucuk dari daunnya tetapi daun yang sudah tua atau daun yang sudah keras[25].

Pada zaman sebelum era modern ini,kebanyakan dalam proses penghalusan daun pepaya masyarakat melakukannya dengan cara menumbuk sampai halus baru menambahkan air dan menyaringnya.Tetapi 
pada era modern ini sudah banyak yang menggunakan blender sehingga mempermudah membuat ekstrak dari daun pepaya tersebut.

Untuk membuktikan kebenarannya,saya melakukan uji coba terhadap ekstrak daun pepaya yang dapat menghilangkan sakit perut ketika datangnya haid[26].Percobaan ini dilakukan dengan cara pembuatan ekstrak daun pepaya dengan menyiapkan daun pepaya yang kualitasnya baik sehingga menghasilkan hasil yang baik,lalu daun pepaya tersebut di cuci dan dipotong-potong agar memudahkan dalam proses penghalusan[27].Setelah mendapatkan ekstraknya lalu menguji cobakan kepada penderita sakit perut saat datangnya haid.Dilihat dari 30 menit pertama rasa sakit masih sangat dirasakan tetapi rasa sakit menghilang ketika rentan waktu 2 jam.Hasil ini membuktikan bahwa ekstrak daun pepaya dapat menghilangkan rasa sakit perut saat datangnya haid.

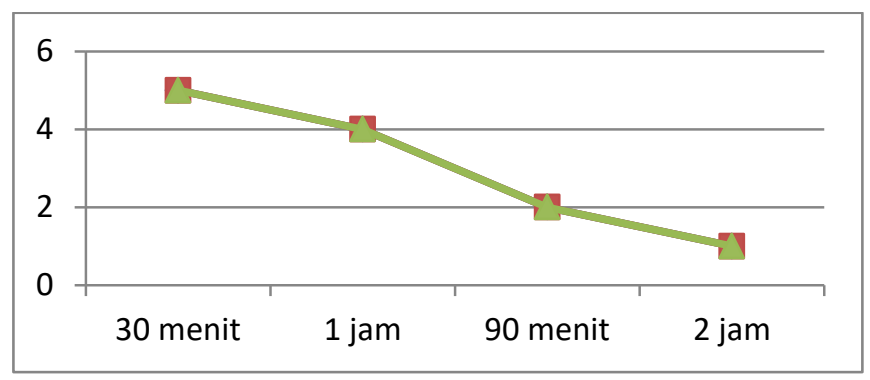

Dari grafik diatas dapat menjelaskan bagaimana rasa sakit itu benarbenar hilang.

A .Pada 30 menit setelah meminum segelas ekstrak daun pepaya rasa sakit pada perut masih terasa sangat sakit

B, Pada 1 jam setelahnya rasa sakit mulai mereda cuma sakitnya masih terasa sekali

C. Pada 90 menit selanjutnya rasa sakitnya sudah mulai menghilang

D. Pada 2 jam setelahnya barulah rasa sakit itu menghilang

Maka dapat disimpulkan bahwa penyembuhan dari meminum ekstrak daun pepaya ini dapat menghlangkan[28]rasa sakit itu pada waktu 2 jam setelah meminum[29][30]segelas esktrak[31] daun pepaya tersebut. 
Daun pepaya memiliki banyak khasiat karena mengandung kalsium dan vitamin A,B,C,D dan E.Kandungan vitamin sangat berguna bagi tubuh karena dapat mencegah terjadinya kanker dan sebagai antioksidan yang membantu mecegah radikal bebas.Daun pepaya juga mengandung saponin dan enzim papain yang berguna untuk mengobati[32][33] gangguan pencernaan,daun pepaya juga dapat membantu peningkatan trombosit[34] pada manusia.Hal ini dibuktikan bahwa rasa pahit[35]pada daun pepaya dapat membantu meningkatkan trombosit pada manusia.

\section{KESIMPULAN}

1 .Ekstrak bisa dibuat dari 2 lembar daun pepaya, 0.5 gram jahe dan 100 $\mathrm{mL}$ air dan menghasilkan ekstraknya $200 \mathrm{~mL}$ air atau setara segelas air

2. Ekstrak ini dapat menyembuhkan pada saat meminum satu gelas ekstrak

3. Ekstrak ini dapat menyembuhkan karena mengandung vitamin

\section{REFERENSI}

[1] Tasim, Lina, Santoso, I R. S., Rombang, W A. R..2013.Analisis Pemahaman Konsep Reaksi Kimia Melalui Pendekatan Pembelajaran Langsung Pada Siswa SMP Negeri 13 Tidore Kepulauan Vol 1, No 3

[2] Erawati Dewi, Luh Joni.2009. Pengembangan Media Pembelajaran Reaksi Kesetimbangan Kimia Vol 6, No 2

[3] Ruswandi, R. (2018) "Determination of Fructose Content resulted by Inulin Hydrolysis with DNS as Oxidizer", EKSAKTA: Berkala Ilmiah Bidang MIPA, 19(1), pp. 14-23. doi: 10.24036/eksakta/vol19-iss1/102.

[4] Dinata, A. A., Rosyadi, A. M., Hamid, S., \& Zainul, R. (2018, October15). A Review CHEMICAL VAPOR DEPOSITION : PROCESS AND APPLICATION. https://doi.org/10.31227/osf.io/yfeau

[5] Febriani, S. S., Yolanda, T., Arianti, V. A., \& Zainul, R. (2018, October 12). A Review Solid Stated : Principles and Methode. https://doi.org/10.31227/osf.io/7us4x

[6] Dinata, M. and Soehardi, F. (2018) "Factor Analysis of Physics Chemistry Waters that Affects Damage Safety Cliff on the Outskirts of 
River Siak", EKSAKTA: Berkala Ilmiah Bidang MIPA, 19(2), pp. 4649. doi: 10.24036/eksakta/vol19-iss2/143.

[7] Sukardi, Sukardi.2001.Antioksidan Alami Sebagai Pengawet Makanan dan Pemeliharaan Kesehatan Tubuh Vol 2No 31

[8] Simanjuntak, Partomuan.2012. TUMBUHAN SEBAGAI SUMBER ZAT AKTIF ANTIMALARIA Vol 23, No 2

[9] Rizqa, Ifan.2010. PERANGKAT LUNAK PENYUSUNAN FORMULA HERBAL SEBAGAI MEDIA PELESTARIAN BUDAYA PENGOBATAN TRADISIONAL KHAS INDONESIA Vol 1, No 1

[10] Winata, Susanty D .2003. Cara Bijak Menggunakan Obat Herbal vol. 11 no. 29

[11] Iskandar, I., Horiza, H. and Fauzi, N. (2017) “EFEKTIVITAS BUBUK BIJI PEPAYA (Carica Papaya Linnaeaus) SEBAGAI LARVASIDA ALAMI TERHADAP KEMATIAN LARVA AEDES AEGYPTY TAHUN 2015”, EKSAKTA: Berkala Ilmiah Bidang MIPA, 18(01), pp. 12-18. doi: 10.24036/eksakta/vol18-iss01/12.

[12] Lasarus, Agnesi.2013. UJI EFEK ANALGESIK EKSTRAK DAUN PEPAYA (Carica pepaya (L.)) PADA MENCIT (Mus musculus) Vol 1, No 2

[13] Faustina, Prapto Yudono, dan Rohmanti Rabaniyah, Ega .2012. Pengaruh Cara Pelepasan Aril dan Konsentrasi KNO3 Terhadap Pematahan Dormansi Benih Pepaya (Carica papaya L.) Vol 1, No 1

[14] Saiya, A. (2017) “ANALISIS RESIDU KLORPIRIFOS DALAM SAYURAN KUBIS DENGAN METODE HPLC DI BEBERAPA PASAR TRADISIONAL DI SULAWESI UTARA", EKSAKTA: Berkala Ilmiah Bidang MIPA, 18(02), pp. 77-85. doi: 10.24036/eksakta/vol18iss02/57.

[15] Kujangke, Freddy.2013. PENGETAHUAN HAID PADA REMAJA DI $M A N A D O$ Vol 1, No 1

[16] Rustam, Erlina.2015.Gambaran Pengetahuan Remaja Puteri Terhadap Nyeri Haid (Dismenore) dan Cara Penanggulangannya.Vol 4, No 1

[17] Rizki Saputra, M. and Sumarmin, R. (2018) "PENGARUH EKSTRAK DAUN SIRIH MERAH (Piper crocatum Ruiz \& Pav.) TERHADAP GLUKOSA DARAH MENCIT (Mus musculus L.) JANTAN YANG 
DIINDUKSI SUKROSA", EKSAKTA: Berkala Ilmiah Bidang MIPA, 19(1), pp. 43-55. doi: 10.24036/eksakta/vol19-iss 1/124.

[18] Putri, D. F., Ritonga, H. M., Murdiati, V., \& Zainul, R. (2018, October 15). A REVIEW WHAT IS HYDROTHERMAL ?. https://doi.org/10.31227/osf.io/dm56c

[19] Sari, A. (2017) "POTENSI ANTIOKSIDAN ALAMI PADA EKSTRAK DAUN JAMBLANG (Syzigium cumini (L.) Skeels)", EKSAKTA: Berkala Ilmiah Bidang MIPA, 18(02), pp. 107-112. doi: 10.24036/eksakta/vol18-iss02/61

[20] Prihatini, R. (2017) "PEMANFAATAN AIR KELAPA UNTUK MENINGKATKAN PERTUMBUHAN AKAR STEK TUNAS AKSILAR Andrographis paniculata Nees", EKSAKTA: Berkala Ilmiah Bidang MIPA, 18(02), pp. 62-68. doi: 10.24036/eksakta/vol18-iss02/54.

[21] Huda, N. (2017) "PENGARUH EKSTRAK SAMBILOTO (Andrographis paniculata Nees.) TERHADAP SIKLUS ESTRUS MENCIT (Mus musculus L. Swiss Webster)", EKSAKTA: Berkala Ilmiah Bidang MIPA, 18(02), pp. 69-76. doi: 10.24036/eksakta/vol18iss02/55.

[22] Zainul, R., Effendi, J., \& M. (2018, December 10). Phototransformation of Linear Alkylbenzene Sulphonate (LAS) Surfactant Using $\mathrm{ZnO}-\mathrm{CuO}$ Composite Photocatalyst. https://doi.org/10.31227/osf.io/fec28

[23] Liza, Y. M., Yasin, R. C., Maidani, S. S., \& Zainul, R. (2018, October 9). SOL GEL : PRINCIPLE AND TECHNIQUE (A REVIEW). https://doi.org/10.31227/osf.io/2cuh8

[24] Susilaningrum, D. (2017) "PEMODELAN REGRESI LOGISTIK PADA FAKTOR YANG MEMPENGARUHI PHBS PADA RUMAH TANGGA PENDERITA TBC DI PESISIR SURABAYA", EKSAKTA: Berkala Ilmiah Bidang MIPA, 18(02), pp. 121-128. doi: 10.24036/eksakta/vol18-iss02/65.

[25] Chatri, M., Mansyurdin, M., Bakhtiar, A. and Adnadi, P. (2017) "PERBANDINGAN KOMPONEN MINYAK ATSIRI ANTARA DAUN MUDA DAN DAUN DEWASA PADA HYPTIS SUAVEOLENS (L.)POIT", EKSAKTA: Berkala Ilmiah Bidang MIPA, 18(02), pp. 112. doi: 10.24036/eksakta/vol18-iss02/41. 
[26] Azhar, M., Ahda, Y., Ihsanawati, I., Puspasari, F., Mawarni, S., Risa, B. and Natalia, D. (2017) "SKRINING BAKTERI PENDEGRADASI INULIN DARI RIZOSFER UMBI DAHLIA MENGGUNAKAN INULIN UMBI DAHLIA", EKSAKTA: Berkala Ilmiah Bidang MIPA, 18(02), pp. 13-20. doi: 10.24036/eksakta/vol18-iss02/44.

[27] Santoso, B. (2018) "IDENTIFIKASI AKUIFER MENGGUNAKAN METODE GEOLISTRIK RESISTIVITAS DI DAERAH BEBANDEM, KARANG ASEM, BALI', EKSAKTA: Berkala Ilmiah Bidang MIPA, 19(1), pp. 24-34. doi: 10.24036/eksakta/vol19-iss1/101.

[28] Yanuar, F., Tillah, M. and Devianto, D. (2018) "Modeling of Human Development Index Using Ridge Regression Method", EKSAKTA: Berkala Ilmiah Bidang MIPA, 19(2), pp. 1-11. doi: 10.24036/eksakta/vol19-iss2/134.

[29] Sofyanita, S. and Octaria, Z. (2018) "Fenthion Compound Degradation in the Pesticide Bayleton 500 ec in Sonolysis, Ozonolysis and Sonozolysis with Addition of TiO2-anatase", EKSAKTA: Berkala Ilmiah Bidang MIPA, 19(2), pp. 70-79. doi: 10.24036/eksakta/vol19iss $2 / 153$.

[30] Desy Kurniawati, Intan Lestari, Harmiwati, Salmariza Sy, Zulkarnain Chaidir, Edison Munaf, Rahmiana Zein, Hermansyah Aziz and Rahadian Zainul.2015. Biosorption of Pb (II) from aqueous solutions using column method by lengkeng (Euphoria logan lour) seed and shell.Vol 7 no 12

[31] Samah, S. (2017) "KARAKTERISASI PLASTIK BIODEGRADABEL DARI LDPE-g-MA DAN PATI TANDAN KOSONG SAWIT", EKSAKTA: Berkala Ilmiah Bidang MIPA, 18(02), pp. 30-38. doi: 10.24036/eksakta/vol18-iss02/48.

[32] Nurfadilah, K. K., \& Zainul, R. (2019, February 3). Kalium Nitrat (KNO3): Karakteristik Senyawa dan Transpor Ion. https://doi.org/10.31227/osf.io/dr8ef

[33] Shafitri, M., \& Zainul, R. (2019, February 3). Vanadium Pentaoksida (V2O5) : Termodinamika Molecular dan Interaksi Ion dalam Larutan. https://doi.org/10.31227/osf.io/jgmvd 
[34] Feronika, N. I., \& Zainul, R. (2018, November 19). Kalium Permanganat: Termodinamika Mengenai Transport Ionik dalam Air. https://doi.org/10.31227/osf.io/g6eyk

[35] Warlinda, Y. A., \& Zainul, R. (2019, January 29). Asam Posfat (H3PO4): Ionic Transformation of Phosphoric Acid in Aqueous Solution. https://doi.org/10.31227/osf.io/s3y8v 